\title{
A Retrospective Study: Trend in the Incidence of Tuberculosis Among Children in the Pekalongan
}

\author{
Irnawati $^{1}$, Benny Arief Sulisyanto ${ }^{2}$, Deisy Sri Hardini ${ }^{3}$, Kosasih Bai Asmita ${ }^{4}$, Tukimin bin Sansuwito \\ ${ }^{1} \mathrm{PhD}$ in Nursing Student, Lincoln University College, Malaysia \\ ${ }^{2}$ Department of Nursing, Faculty of Health Sciences, Universitas Muhammadiyah Pekajangan Pekalongan, Indonesia \\ ${ }^{3}$ Department of Nursing, Faculty of Health Sciences, University of Muhammadiyah Purwokerto, Indonesia \\ ${ }^{4}$ Master of Nursing Student, Lincoln University College, Malaysia \\ ${ }^{5}$ Faculty of Applied Sciences, Lincoln University College of Malaysia
}

\section{ARTICLE INFO}

Article history:

DOI:

10.30595/pshms.v2i.223

Submitted:

December 6, 2021

Accepted:

January 21,2022

Published:

January 26, 2022

\begin{abstract}
Mycobacterium tuberculosis is the leading cause of death worldwide from a single bacterial pathogen. World Health Organization (WHO) estimates that annually, 1 million children have tuberculosis disease and many more harbor a latent form of infection. Evaluation of time trends is an integral part of a comprehensive analysis of tuberculosis among children data. Objective: This study aimed to assess trends in tuberculosis among children incidence in the period 2015-2021. Tuberculosis among data were collected from tuberculosis database of Pekalongan Health Department. Data were analyzed by using Microsoft Excel. In the period 2015-2019, the tuberculosis among children incidence significantly increased from 11 to 165 cases, then drop in the period 2019-2021 from 165 to 32 cases. The largest increase in trend in the analysed period was observed for 2019, which showed an increase of 165 cases. Knowledge of the current tuberculosis among children burden in the population and its time trends will help to prioritise targets and future resource allocation to tuberculosis among children control.
\end{abstract}

Keywords:

Epidemiology, tuberculosis, incidence, time trend, pekalongan

This work is licensed under a Creative Commons Attribution 4.0 International License.

Corresponding Author:

Irnawati,

$\mathrm{PhD}$ in Nursing Student,

Lincoln College University, Malaysia

6/12 SS Road, Petaling Jaya, Selangor Darul Ehsan 47301, Malaysia.

Email: sakinah.jogja@ymail.com

\section{INTRODUCTION}

Globally, tuberculosis (TB) is the leading cause of infectious disease mortality; however, clinicians in the United States are increasingly unfamiliar with tuberculosis and the recommended tests and treatment for latent tuberculosis infection. Compared with adults, children who develop tuberculosis more often develop severe disease, and children $<2$ years are particularly susceptible to developing tuberculosis disease after initial infection. At least half a million children become ill with tuberculosis each year. Up to 74000 children die of tuberculosis every year [1].

In 2017, approximately 10 million people, including 1 million children, developed TB disease (ie, active TB with clinical signs or symptoms of TB, or both) worldwide, and 1.3 million died, including at least 233,000 children.1 TB is the ninth leading cause of death worldwide and the leading cause of death from a single in- fectious agent, ranking above HIV/AIDS. Tuberculosis is curable with anti- biotic treatment[2]. In most regions of the world, LTBI is not a reportable condition to public health authorities, making prevalence 
estimates challenging. Estimates suggest that > 50 million children worldwide have laten tuberculosis infection [3].

Globally at least US\$ 80 million per year will be required to address childhood tuberculosis. An additional US\$ 40 million per year will be needed for antiretroviral therapy and co-trimoxazole preventive therapy for children co-infected with tuberculosis[4]. Tuberculosis is caused by bacteria[5]. It's most often caused by Mycobacterium tuberculosis. Many children infected with Mycobacterium tuberculosis never develop active tuberculosis and remain in the latent tuberculosis stage[6].

The proportion of pediatric tuberculosis cases among all tuberculosis cases in Indonesia in 2010 was $9.4 \%$, then to $8.5 \%$ in $2011,8.2 \%$ in $2012,7.9 \%$ in $2013,7.16 \%$ in in 2014 and $9 \%$ in 2015 . The proportion varies between provinces, from $1.2 \%$ to $17.3 \%$. This variation in proportion may indicate different endemicity between provinces[7].

Millennium Development Goals 4 and 5 aim to reduce deaths among children and pregnant women, while MDG 6 focuses on turning around the tuberculosis[8]. Children with tuberculosis are often poor and live in vulnerable communities where there may be a lack of access to health care[9]. Like adult tuberculosis, tuberculosis can occur in any site of the body in children, but mainly occurs in the lungs (pulmonary tuberculosis)[10]. Following inhalation to the lungs, Mycobacterium tuberculosis bacilli may disseminate to other organs via haematogenous spread, causing extra-pulmonary tuberculosis[11]. Cervical lymphadenitis (also known as scrofula or The King's Evil) is the most common phenotype of extrapulmonary tuberculosis for children, followed by tuberculous meningitis[5]. Miliary tuberculosis and tuberculous meningitis are among the most severe extrapulmonary tuberculosis presentations[4]. Other extrapulmonary sites are described less commonly including the eyes, larynx, middle ear, mastoid, genitourinary and intestinal tract, pleura, skin[12]. Factors contributing to disease presentation include: the age at time of primary infection and the time elapsed since infection[13]. Very young children and immunosuppressed children are more at risk of severe tuberculosis. Children may also acquire infection with Mycobacterium bovis through the drinking of unpasteurised milk and "BCG-osis" may occur in children with HIV, following BCG vaccination[14]. For this reason BCG vaccination is not recommended in known HIV positive children[15]. Evaluation of time trends is an integral part of a comprehensive analysis of tuberculosis among children data[16]. This study aimed to assess trends in tuberculosis among children incidence in the period 2015-2021.

\section{RESEARCH METHOD}

This retrospective study that included all tuberculosis among children cases in Pekalongan City [17]. This study used the database of the of Pekalongan Health Department from 2015-2021. The Pekalongan Health Department database contains record on all tuberculosis diagnosed in the Pekalongan City, Central Java, Indonesia. Pulmonary tuberculosis were analyzed in this study [18]. Use of research design intended to obtain a trend patients with relapse pulmonary tuberculosis who seek treatment in all public health centers and hospitals in Pekalongan City from 2015 to June 2021.

In the tuberculosis program in Pekalongan City, children with tuberculosis symptoms from general hospitals and community health centers are referred to designated tuberculosis hospitals or clinics for confirmation and diagnosis by sputum smear test and bacterial culture. Pekalongan Health Department established a surveillance system and mandatory routine reporting of tuberculosis among children cases. The routine surveillance system records demographic, clinical and laboratory information on every children diagnosed with tuberculosis. Ethical was approved by Research and Development Planning Agency (BAPPEDA) No. 070/214/VI/2021 in Pekalongan, Indonesia.

\section{RESULT AND DISCUSSION}

Proceeding homepage: https://conferenceproceedings.ump.ac.id/index.php/pshms/issue/view/10 


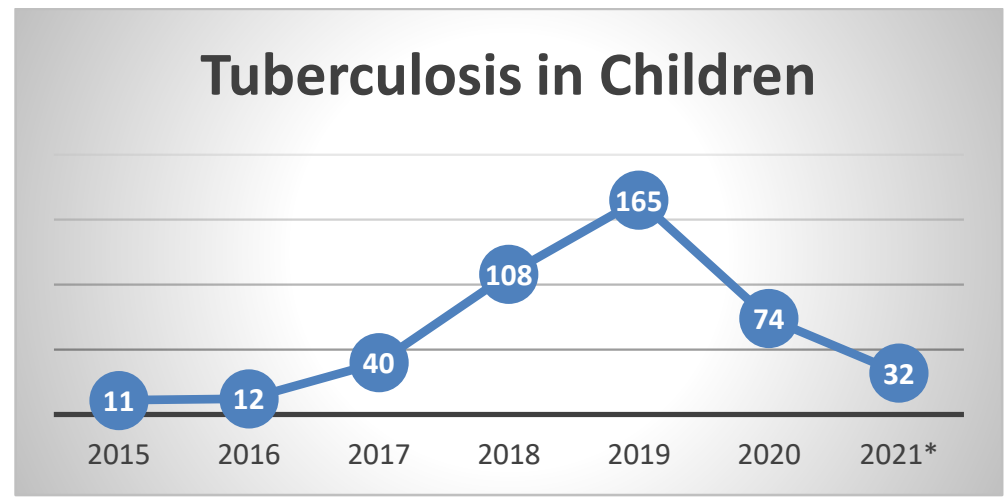

Figure 1. Trends in Tuberculosis Among Children Incidence in the Period 2015-2021 in Pekalongan

Figure 1 illustrates tuberculosis among children under 14 years in the period 2015-2019. In 2015, there were 11 cases of tuberculosis in children. Cases increased in 2016 to 12 cases of tuberculosis in children. Tuberculosis cases in children increased sharply in 2017 to 40 cases. In 2018 cases of tuberculosis in children increased 3 times from 2017 to 108 cases. Then in 2019 cases of tuberculosis in children increased to 165 cases and became the highest case during the period 2015-2021. Then in 2020 cases of tuberculosis in children decreased 2-fold to 74 cases. Then in 2021 cases of tuberculosis in children continued to decline to 32 cases. Tuberculosis among children incidence significantly increased from 11 to 165 cases, then drop in the period 2019-2021 from 165 to 32 cases. The largest increase in trend in the analysed period was observed for 2019, which showed an increase of 165 cases in children under 14 years.

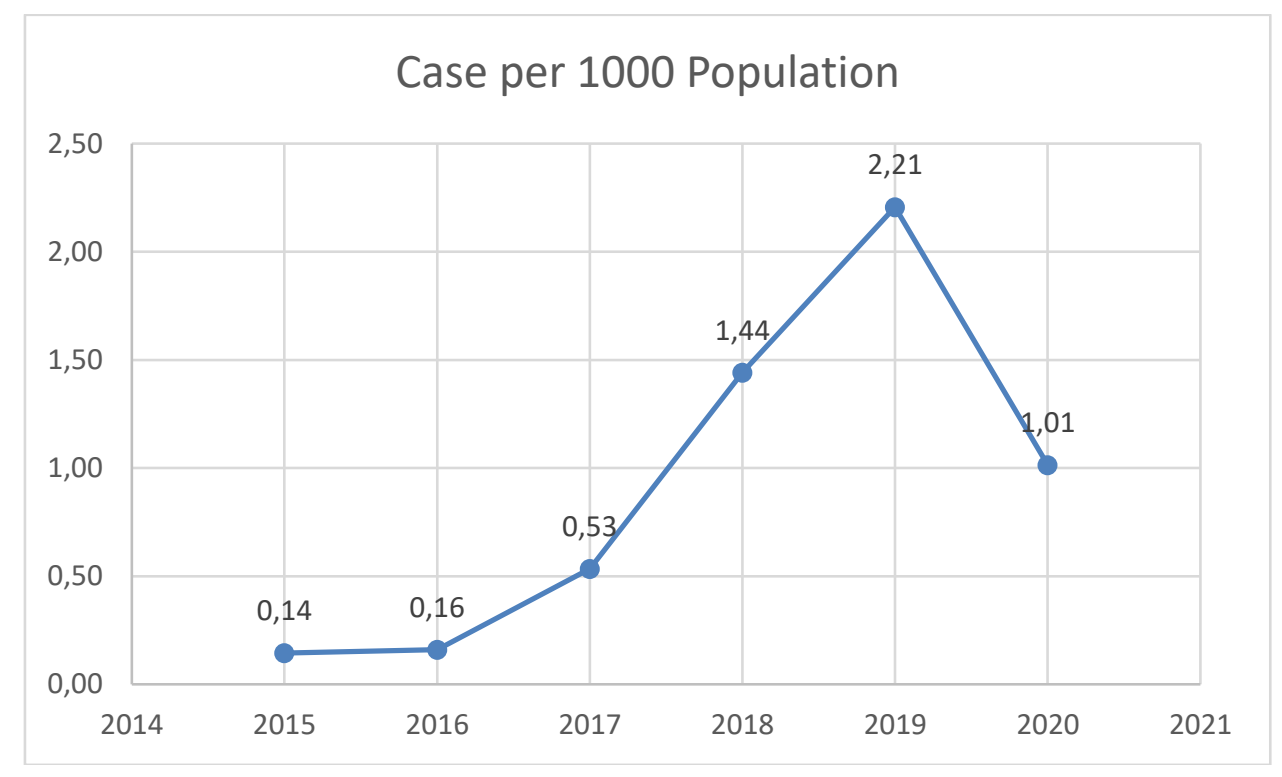

Figure 1. Trends in Tuberculosis Among Children Incidence per 1000 Population of children in the Period 2015-2021 in Pekalongan

Figure 2 illustrates tuberculosis among children in the period 2015-2019 per 1000 population of children in Pekalongan, Central Java, Indonesia. In 2015, there were 0.14 cases per 1000 child population in Pekalongan. Cases increased in 2016 to 0.16 tuberculosis cases per 1000 child population. Tuberculosis cases in children increased sharply in 2017 to 0.3 cases per 1000 child population. In 2018 cases of tuberculosis in children increased 3 times from 2017 to 1.44 cases per 1000 child population. Then in 2019 cases of tuberculosis in children increased to 2.21 cases per 1000 population of children and became the highest case during the 2015-2021 period. Then in 2020 cases of tuberculosis in children decreased 2-fold to 1.01 cases in children under 14 years[19].

Estimated cases of tuberculosis in children in Indonesia from 845,000 Indonesian population, $17 \%$ of children diagnosed with tuberculosis. Data until June 14, 2021, cases of tuberculosis in children reached 33,336 cases. The incidence of tuberculosis per 100,000 population in Indonesia is 272 cases in 2020 and 252 cases in 2021. Tuberculosis cases in children in 2019 were 2.21 cases per 1000 child population in Pekalongan as high as tuberculosis cases in Indonesia in 2021, namely 2.52 cases per 1000 total population of tuberculosis[20]. 
Globally, the tuberculosis incidence rate in the world is falling, but not fast enough to reach the first milestone of the End TB Strategy; that is, a 20\% reduction between 2015 and 2020. Worldwide, the cumulative reduction from 2015 to 2019 was $9 \%$ (from 142 to 130 new cases per 100000 population), including a reduction of $2.3 \%$ between 2018 and 2019. Tuberculosis cases in children in 2019 were 2.21 cases per 1000 population of children in Pekalongan, which was higher when compared to tuberculosis cases in the world in 2015-2019, namely $1.42-1.30$ cases per 1000 total population of tuberculosis[21]

Children who inhabit the same house with tuberculosis patients are at high risk for infection and illness with tuberculosis[9]. Tuberculosis in children is often missed or overlooked due to non-specific symptoms and difficulties in diagnosis[22]. This has made it difficult to assess the actual magnitude of the childhood tuberculosis epidemic. Any child living in a setting where there are people with infectious TB can become ill with TB, even if they are vaccinated[23]. The pathophysiology and clinical presentation of TB differ according to age. The WHO classifies as children individuals aged up to 14 years [24]. This age cutoff defines the research flows and therapeutic conducts[12].

Children have a nonspecific clinical picture similar to usual childhood infections and are paucibacillary. As for adolescents (older than 10 years), they develop disease similar to that in adults, and can have bacilliferous pictures. In children under 10 years of age, due to paucibacillary form and sputum collection difficulties, the diagnosis is based on a scoring system, which evaluates the clinical and epidemiological history, tuberculin skin test (TST) response, chest X-ray, and the patient's nutritional status.

It is known that not every child with a latent infection will develop active tuberculosis. Children under 5 years or those with immunodeficiency have an increased risk of disease progression, but the understanding of risk factors for this occurrence is limited. Whittaker

\section{CONSLUSION}

In summary, this study has shown that there is a relatively high rate of tuberculosis among children in Pekalongan City when compared to tuberculosis cases in the world. Children under five years of age who have close contact with tuberculosis cases should be targeted for priority interventions to prevent the transmission of tuberculosis infection and progressing to tuberculosis cases. The need to establish a more efficient tuberculosis prevention and control strategy in Pekalongan City still remain. The development of improved techniques for identifying tuberculosis among children has essential implications for understanding tuberculosis epidemiology and the implementation of related technologies in tuberculosis control programs, patient management, and outcome analysis of clinical trials [25]. Knowledge of the tuberculosis among children burden in the population and its time trends will help to prioritise targets and future resource allocation to tuberculosis among children control. Nurse practitioners who work in primary care are on the front lines of identifying children at high risk and obtaining testing and treatment.

\section{Acknowledgements}

The author would like to thank the University of Muhammadiyah Pekajangan Pekalongan for their financial support in this project. Appreciation also extended to Pekalongan Health Department for provided research data that supported the research.

\section{REFERENCES}

[1] R. J. Stewart et al., "Tuberculosis Infection in Children," TJNP J. Nurse Pract., vol. 16, no. 9, pp. 673-678, 2020, doi: 10.1016/j.nurpra.2020.06.027.

[2] S. M. Ajibade, O. O. Adewoye, and T. H. Akin-Olayemi, "International Journal of Research in Mechanical," vol. 10, no. August, pp. 1818-1820, 2014.

[3] A. Turkova et al., "Prevalence, incidence, and associated risk factors of tuberculosis in children with HIV living in the UK and Ireland ( CHIPS ): a cohort study," Lancet HIV, vol. 2, no. 12, pp. e530-e539, 2015, doi: 10.1016/S2352-3018(15)00200-3.

[4] S. Valencia, M. León, I. Losada, V. G. Sequera, M. Fernández Quevedo, and A. L. García-Basteiro, "How do we measure adherence to anti-tuberculosis treatment?," Expert Rev. Anti. Infect. Ther., vol. 15, no. 2, pp. 157-165, 2017, doi: 10.1080/14787210.2017.1264270.

[5] C. Rapezzi, "Bacterial Factors and Relapse after Tuberculosis Therapy," N. Engl. J. Med., vol. 380, no. 2, pp. 196-197, 2019, doi: 10.1056/nejmc1814074.

[6] M. F. Sarah S. Long, Charles G. Prober, Principles and Practice of Pediatric Infectious Diseases, Fifth edit. Philadelphia, New York, London: Elsevier Health Sciences, 2018.

[7] Kemenkes RI, Petunujuk teknis tatalaksana TB Pada anak. Jakarta: Kementrian Kesehatan Republik Indonesia, 2016.

[8] T. U. Nations and L. Pdr, "From Millennium Development Goals to Sustainable Development Goals: Laying the base for 2030," no. November, 2017. 
[9] WHO, Guidelines for treatment of drug-susceptible tuberculosis and patient care. Switzerland: World Health Organization, 2017.

[10] M. Easwaran et al., "Knowledge, attitude, and practice regarding tuberculosis among rural population in Tamil Nadu," Int. J. Med. Sci. Public Heal., vol. 4, no. 12, p. 1681, 2015, doi: 10.5455/ijmsph.2015.08052015344.

[11] X. Shen et al., "Recurrent tuberculosis in an urban area in China: relapse or exogenous reinfection?," HHS Public Access, pp. 97-104, 2018, doi: 10.1016/j.tube.2017.01.007.Recurrent.

[12] P. G. T. Cudahy, D. Wilson, and T. Cohen, "Risk factors for recurrent tuberculosis after successful treatment in a high burden setting: a cohort study," BMC Infect. Dis., vol. 20, no. 1, pp. 1-8, 2020, doi: 10.1186/s12879-020-05515-4.

[13] G. D. Van Der Spuy, P. D. Van Helden, and N. Beyers, "The temporal dynamics of relapse and reinfection tuberculosis after successful treatment: a retrospective cohort study," Clin. Infect. Dis., 2014.

[14] Y. Liu, X. X. Zhang, J. J. Yu, C. Liang, Q. Xing, and C. Yao, “Tuberculosis relapse is more common than reinfection in Beijing, China Tuberculosis relapse is more common than reinfection in Beijing, China," Infect. Dis. (Auckl)., vol. 0, no. 0, pp. 1-8, 2020, doi: 10.1080/23744235.2020.1794027.

[15] T. T. SINH, "Tuberculosis in children. Diagnosis and treatment," Ann. Nestle, vol. 55, no. 1, pp. 1023, 2016, doi: 10.21954/ou.ro.0000bd2a.

[16] P. Sonnenberg, J. Murray, S. Shearer, J. R. Glynn, B. Kambashi, and P. Godfkey-faussett, "Tuberculosis failure and drug resistance-same," R. Soc. Trop. Med. Hyg., no. March, 2000.

[17] B. Marr, Big Data Using Smart Big Data Analytics and Metrics to Make Better Decisions and Improve Performance. Cornwall, UK: Wiley, 2015.

[18] C. Polit, DF, Beck, Essentials of Nursing Research Appraising Evidence for Nursing Practice, Seventh Ed. Philadelphia, New York, London: Lippincott Williams and Wilkins, 2010.

[19] S. of P. Municipality, "Jumlah Penduduk Menurut Kelompok Umur," Statistics of Pekalongan Municipality, 2021. https://pekalongankota.bps.go.id/indicator/12/165/1/jumlah-penduduk-menurutkelompok-umur.html (accessed Oct. 08, 2021).

[20] K. RI, “TBC Indonesia,” Kementrian Kesehatan Republik Indonesia, 2021. https://tbindonesia.or.id/ (accessed Oct. 08, 2021).

[21] WHO, Global Tuberculosis Report 2020. World Health Organization, 2020.

[22] K. Ge. F, National Tuberculosis Prevalence Surveys : 2007-2016. 1967.

[23] WHO, "Global Tuberculosis Programme," 2021. https://www.who.int/teams/global-tuberculosisprogramme (accessed Jun. 08, 2021).

[24] T. T. Tahan and A. M. O. Rossoni, "Tuberculosis in childhood and adolescence: a view from different perspectives ๕ , ๕๕," J. Pediatr. (Rio. J)., vol. 96, pp. 99-110, 2020, doi: 10.1016/j.jped.2019.11.002.

[25] A. Mcivor, H. Koornhof, and B. D. Kana, "Relapse, re-infection and mixed infections in tuberculosis disease," no. December 2016, pp. 1-16, 2018, doi: 10.1093/femspd/ftx020. 